\title{
Magnesium, insulin resistance and body composition in healthy postmenopausal women
}

DOI: 10.1080/07315724.2004.10719391

Maria J. Laires PhD ${ }^{a^{*}}$, Helena Moreira PhD ${ }^{c}$, Cristina P. Monteiro ${ }^{a}$, Luis Sardinha PhD ${ }^{b}$, $\underline{\text { F. Limão }}^{a}, \underline{\text { Luisa Veiga }}^{{ }^{d}}, \underline{\text { Alice Gonçalves }}^{\mathrm{b}}, \underline{\text { A. Ferreira }}^{\mathrm{a}}$ \& Manuel Bicho MD ${ }^{\mathrm{e}}$

pages $510 \mathrm{~S}-513 \mathrm{~S}$

Publishing models and article dates explained

Received: 5 Aug 2004

Published online: 18 Jun 2013

\section{Abstract}

Objective: This study was conducted to determine the association between magnesium (Mg), body composition and insulin resistance in 136 sedentary postmenopausal women, 50 to 77 years of age.

Methods: Diabetics, hypertensives and women on hormonal replacement therapy were excluded and the remaining 74 were divided according to $\mathrm{BMI} \geq 25$ (obese: $\mathrm{OG}$ ) and $\mathrm{BMl}<25 \mathrm{~kg} / \mathrm{m}^{2}$ (non-obese: NOG). Nutritional data disclosed that intakes were high for protein and saturated fat, low for carbohydrates, polyunsaturated fat and $\mathrm{Mg}$ and normal for the other nutrients, according to recommended dietary allowances (RDA). $\mathrm{Mg}$ values in red blood cells (RBC-Mg) and plasma (P-Mg), were determined, as were fasting glucose, and insulin levels, Homeostasis Model Assessment (HOMA), body mass index (BMI), body fat percent (BF \%), abdominal fat (AF) and free fat mass (FFM).

Results: RBC-Mg values were low in both groups when compared with normal values. There were significant differences in body composition parameters, HOMA and insulin levels, with higher basal insulin levels in OG. RBC-Mg was directly correlated with insulin, HOMA and FFM in both groups, according to Pearson correlations. HOMA in OG was also directly correlated with BMI, FFM and AF. In NOG, HOMA was only 
correlated with FFM. The low RBC-Mg levels observed were probably due to low $\mathrm{Mg}$ intake and to deregulation of factors that control $\mathrm{Mg}$ homeostasis during menopause.

Conclusions: Both Mg deficit and obesity may independently lead to a higher risk for insulin resistance and cardiovascular disease.

- View full text

- Download full text

- $r b c \mathrm{Mg}$,

- serum $\mathrm{Mg}$,

- Mg deficiency,

- insulin resistance,

- body composition

- postmenopause,

- fat-distribution,

- obesity

\section{Details}

- Received: 5 Aug 2004

- Published online: 18 Jun 2013

Routledge

Taylor \& Francis Group

\section{Author affiliations}

- ${ }^{a}$ Biochemistry Laboratory (M.J.L., C.P.M., F.L., A.F.), PORTUGAL

- ${ }^{b}$ Exercise and Health Laboratory (L.S., A.G.), PORTUGAL

- $\quad$ ' Faculty of Human Movement, U.T.L., Cruz Quebrada, Sports Department, University of Trás-os-Montes e Alto Douro, Vila Real (H.M.), PORTUGAL

- ' U.T.L., Lisbon's School of Health Technologies (L.V.), PORTUGAL

- ${ }^{\mathrm{e}}$ Genetics Laboratory, Faculty of Medicine, U.L., Lisboa (M.B.), PORTUGAL 